\title{
Creating a Handbook to Describe Employee Benefits for PT. WY's New Employees
}

\author{
Florensia Nadya Lovillea \\ English Department, Faculty of Languages and Literature, Petra Christian University, Siwalankerto 121- \\ 131, Surabaya 60236, INDONESIA \\ E-mail: florensianadya97@gmail.com
}

\begin{abstract}
PT. WY is a manufacturing company which produces household and personal care products. Their main target market is family. The main problem is that new employees have no idea what to expect from this company, since there is no written information about employee benefits. Based on interviews and surveys, most employees did not know about the employee benefits of PT. WY, and the HRD representatives also agreed that they often asked about it. PT. WY actually has the handout, however, it is not complete yet, so they did not use it. Therefore, the solution is a handbook to describe employee benefits for the new employees. This project is done after reviewing theories by Bloomfield, Schofield, and Cantesbury (2015) and Martocchio (2016) and information from the company. This handbook is expected to help the company and its employees to always refer every information to the handbook.
\end{abstract}

Keywords: employee, benefits, handbook

\section{INTRODUCTION}

The company where I did my project and internship was PT. WY. PT. WY is a manufacturing company in Surabaya which produces household and personal care products. The main target of this company is average Indonesian family regardless of their gender. During internship, I worked as the recruitment staff in Human Resource Department (HRD). The main problem in HRD is that many new employees still have no idea what to expect from PT. WY, because there is no written information about things needed by the employees, like company policies and employee benefits. This problem happened because the company only give them a brief information about it in the orientation session, so there are still many new employees asked about it. They actually have the employee benefits draft, but they never distribute it to the employees. I also did a survey for the employees to know about this problem, and most of them said that they did not really understand about the company policies and employee benefits and wanted to know more about it.

In making the handbook, there are some theories needed in order to make sure that the handbook indeed helpful to the company and the employees. The main theories used in this process are handbook and employee benefits. Mayangsari (2016, p. 79) stated that an employee handbook is a small book of rules and regulation or policies and procedures for the employees to obey and to agree. Heathfield (2019) stated that employee handbook is a compilation of information to guide employees in a workplace. The contents can be policies, procedures, working conditions, and behavioral expectations. In other words, employee handbook is basically a guidebook or manual for the employees, so they know what they can do, what they need to do, and what they can expect from the company. Heathfield (2019) also mentioned that most handbooks also clearly stated about employee compensation and benefits. According to Bloomfield, Schofield, and Cantesbury (2005, pp. 221-222), handbook is beneficial for the employees to adapt to the company. It does not have to be a very good employee handbook, because the most important part is the content. It must to be information that is needed by the employees. The second main theory is employee benefits, since the content of the handbook is 
employee benefits. Basically, employee benefits refer to compensation other than salary given to employees. It is used to balance the salary and the non-salary compensation (Martocchio, 2016, p. 4). The company can use the employee benefits to motivate the employees to perform better in the company. It also can assure the employees that every work they have done will be paid-off equally. The other theories used in making this handbook are mostly the content of the handbook, which is the benefits. There are many types of employee benefits, such as health insurance, pension or retirement plan, paid leave, sick leave, paid vacation, etc.

\section{METHODS}

The tool used to solve the company's problem is a handbook for the new employees that contains explanation about employee benefits of PT. WY. The handbook will be given to the new employees on their first day of working in the company, and will be taken back when they stop working in the company. At first, the handbook will contain company policies and employee benefits, since most of employees in PT. WY has requested to know about the company policies and employee benefits. However, in order to focus on one problem that is more important, the content of the handbook was changed into employee benefits only. Moreover, the explanation of the employee benefits will be more detailed. In order to make the employee understand better about the explanation, the handbook is written in Indonesian, since there is no foreign employees in PT. WY. The concept of the handbook is simple, it is only white background and red pattern. White color is used as the background, to make the explanation clearer to the readers, and red color is used to represent the company image. By having the handbook, the employees are expected to understand better about what they get as employees in PT. WY. It also helps the company, so they do not have to keep explaining to each employee who asked about the information.

There were several steps taken in the process of the handbook. First, I interviewed the HRD representative to know about the problem in the HRD. From the interview, it is found that the problem is the employee who have no idea about what to expect from the company. Other than interview, a survey was also conducted for the employees to know their opinion about information that they did not know, and they want to know. Since there was not much information, I only did a small survey with one question for the employees. The result of the survey is that most of them did not really know about the company policies and employee benefits of PT. WY, so they did not know what to expect from the company. However, since more of the employees wanted to know about the employee benefits, I chose to focus on the employee benefits only. The HRD representatives also said that the employee benefits are the main concern right now. After that, I listed down the theories each benefit and made an outline about it, and then discussed the theories with the representative. It turned out that they already have the rough draft about the employee benefits I can refer to. So, they gave the draft and I made a major revision by adding other explanations and sub-chapters about the benefits in order to complete the handbook. I started by reading the draft thoroughly and found that some information is unclear and incomplete. So, I revised the draft by giving highlight to the incomplete or unclear parts. After highlighting all the unclear and completing the incomplete parts, I added several information based on the verbal information from the HRD. I referred all the information I added to the theories, and discussed it with the representative. After they added the missing information to the draft, I started to design the handbook until it is finished and ready to be used by the PT. WY.

\section{FINDINGS AND DISCUSSION}

In this part, I will explain the rationale of the products, including an explanation or the reason why I chose the contents of the handbook. In making the handbook, all the information is written in a clear, concise, and understandable language (Snell and Bohlander, 2010, p. 495), 
which is Indonesian, since all of the employees in PT. WY are Indonesian. The company also tried to explain all the benefits in an open and honest manner. For the design or concept of the handbook, the background will be white, to make the writing clear. There will be a red pattern since it is the color of the logo. All the design follows the color and the image of PT. WY. To sum up the explanation of the findings, I divided the explanation into three parts. The first part is the major revisions I have done for making the handbook. In the major revisions, I added missing information to the draft and new sub-chapters to complete the handbook. Since the draft from the company contains only the content of the handbook, I added other titles beside the employee benefits explanation, such as "Policy Disclaimer", "Purpose of the Handbook", "Insurance", "Unemployment Compensation", "Food Service", "Minimarket", "Employee Training Program", "Employee Counseling Program", "Employee Wellness and Health Program", and "Retirement Plan". Other than "Insurance" and "Unemployment Compensation", the other titles and sub-chapters are excluded from the draft. I added "Policy Disclaimer" to make sure that the employees know how the handbook works for them. As the definition of disclaimer, this part is used as an advanced warning or information about the handbook, so that the user will understand if there is changes from the company. In addition, with disclaimer, the company can always refer to it, if there is something the company wants to add in the handbook. There is also "Purpose of this Handbook". The reason of "Purpose of this Handbook" is simply to tell the employees the reason why the company makes the employee handbook for the employees, so that they know what to do with the employee handbook. I also added "Food Service", "Minimarket", and "Employee Wellness and Health Program" because I know that those things are provided for the employees in PT. WY, but the company did not write it in the draft. In these parts, I explained that PT. WY provides a food service for its employees in lunch break, minimarket for the employees to buy any product produced by PT. WY in a cheaper price, and a fit club called WY Fit Club to make sure that the employees will always stay healthy and fit. In WY Fit Club, there are several kinds of sport, like yoga, calisthenics, aerobics, zumba, badminton, etc., that can be joined by the employees. For "Employee Counseling Program", "Employee Training Program", and "Retirement Plan", I am sure every company will have these kinds of benefit for its employees. Therefore, I added these subchapters to the handbook based on the theories I have found. In "Employee Counseling Program" and "Employee Training Program", I explained that each benefit surely has advantage for both the company and the employees. Beside that the employees can have counseling time with their superiors, they also can get training programs to train and improve their skills in the company. In the training program, there are three types of training, which are basic skills training which focuses on the reading, writing, and computation skills that is needed to function in most of jobs; technical training which refers to training that can improve technical skills, like computer, safety, and quality training; and interpersonal training which focuses in the individual relationship with others, like communication, customer relations, sales training, and team building). The last sub-chapter I have added is "Retirement Plan" that I am sure every company has for their employees to prepare their future where they are no longer earning a steady income from employment. There are also requirements for the retirement plan which are added to the draft, so it can be clearer for the employees. For "Insurance" and "Unemployment Compensation", I added a further information so that it became clearer to the readers. In the "Insurance" part, there are additional points in this part, which are things that is not covered by insurance in PT. WY. It is because, before revision, the information is too general for people who read it. They may not understand clearly about PT. WY's policy in this part. Whereas, in "Unemployment Compensation" part before it was revised, there is no specific period for the employees to get the compensation. It is written that the company requires to pay compensation to employees who are unemployed by the company as the substitute for their lost income. Therefore, further explanation was added into this part, which are about actions that lead into an unemployment, and how compensation can be given to the employees. 
The second revision I have done in making the handbook is minor revisions in which I only added minor information that is missing from the draft, for example "Table of Contents", "About Us", "Karakter WY Profesional", and "Nilai Bisnis". Those four titles were added to introduce the handbook to the reader. The purpose of "Table of Contents" is to make sure that the employees can use the handbook efficiently. It will be easier for the employees to find what they want to read in the handbook, they can open the table of the contents to know in what page the information they want to read is. While, "About Us", "Karakter WY Profesional", and "Nilai Bisnis" were added as the request of the company. These parts are used to introduce the company briefly to the employees. With these information, the employees will know the short history of PT. WY, the professional character that every employee must have in PT. WY, and the business value of PT. WY.

There are also several parts in which I made a minor revision in it. The first part with minor revision is "Time Records" which explains the employees must present and check lock at least five minutes before the working hours start and at least fifteen minute after the working hour ends. After revision, there is an additional information about the employees working hours in a day and a week. The second part is "Employee Allowance". In this part, the information is very short and not very clear. So, an additional explanation was added to make it clear, which is the types of allowance the employees will get. The third part is "Medical Leave Policy". In this part, the company explains that medical leave does not affect personal leave and paid time-off or paid vacation. However, it is still not very clear, so some explanation was added to the draft. The additional explanation is about women employees who are sick because of their period or miscarriage. The fourth part is "Voting". Voting is an obligation for Indonesian citizen; therefore, it becomes a national holiday for all citizen in the country. Before it gets revised, PT. WY give a benefit for the employees to have a voting leave, if the voting happens in a working days. However, since voting day becomes a national holiday, it was excluded from the handbook. The fifth part is "Maternity Leave". In PT. WY, there is a maternity leave benefit for pregnant women who are sick or giving birth, however, this benefit can be given after the company receive a proof from the related hospital. There are two steps that the employees have to do after they are approved to have maternity leave. If there is any employee who is no longer have leave periods, the company can give them paid leave to extend her leave period. In PT. WY, the employees can ask for a hospital letter to know the time estimation that is needed by the employees to rest before and after giving birth. Before revision, PT. WY did not give a specific duration for how long a pregnant woman can have a maternity leave. Because it is not clear, it gets revised by adding a specific duration for pregnant employee to have a maternity leave. The sixth part is "Employee Discounts". It is an optional benefit given by PT. WY. This benefit provided discounts from several vendors related to the company for the employees. PT. WY usually cooperates with several vendors which have a potential to work with them to provide discount for the employees. However, since it is not clear about when the employees will get the discount, an additional explanation that the discount is applied only when there is an event in the company was added to the draft. The seventh part is "Educational Assistance". PT. WY encourages its employees to improve their skills and knowledge through education. PT. WY believes that the improvement of its employees can give a positive impact and an advancement for the company. However, before revision is made, PT. WY does not give that requirement to the employees. PT. WY only wrote that employees who want to apply for major and classes, must give a specific reason why they choose that major. After revision was made, PT. WY stated that request for training is only allowed if it is related to the employees' current jobs and when it is needed to improve their job performance. The last part in this minor revision is "Company Sponsored Events". Every year, PT. WY gets proposals to sponsor any kind of event, like sport, museum, theater, amusement park, party, etc. However, there is no further explanation about the employees' role in the event. So, it is added that employees can participate as participant or guest. In addition, the sponsored events will be helped by Marketing Support Department of PT. WY. 
The last part is parts where I did not add any further information nor revise the content because the explanation was already clear and complete. The first part is "Benefit Eligibility" which explains about employee classification which will get the benefits from PT. WY. There are two types of employee, which is full-time employee and management trainee. Full-time employees will get all the benefits provided by PT. WY. Whereas, the management trainee will get only the specific benefits that has been arranged by PT. WY. This part is important for the employees, so they know exactly what their status are and what benefits they will get. After "Benefit Eligibility" part as the head-chapter of the employee benefits, there is "Payroll Information" as the first sub-chapter. In this part, there is an explanation that employees should fill in an insurance form and submit it to the HRD. The purpose of filling out a form is to make the distribution of the salary can run correctly. The second part "Salary Compensation for Partial Pay Period" which explain that employees whose salary is less than the salary standard of the company because of unpaid leave or resignation in a specific month, should be calculated consistently as how long they were working in that month. The third part is "Payroll Deduction". In this part, the company explains that they have an authority to deduct their salary for the uniform cost, insurance cost, taxes, pension plan, and other costs in the company. However, the employees will get the receipt for that deduction as a proof. The fourth part is "Payroll Errors". In this part, the company inform the employees that they will try to pay the employees' salary on time. However, if there is any error in the payroll, they can report it to the HRD Manager, so it can be solved at least before the next payroll. Fifth part is The last part is "Pay at Time of Separation". This part explains information that the employees need to know before resigning or unemployed from work, like credit card, uniform, car, even debt. After everything is calculated, they can receive the salary. The fifth part is "Paid Vacation". This benefit allows the employees to get paid even when they are not performing in the company. As Martocchio (2006, p. 247) said, vacation days may be viewed as a reward for employees. That is why in PT. WY, the employees are given a paid vacation benefit. In the handbook, the company explains that the employees get an amount salary equal with the usual salary per month.

However, the company informs that the paid vacation cannot be given as an overtime compensation. The sixth part is "Holidays". In this sub-chapter, the company explains that the holiday schedule in PT. WY is the same with the National Holiday in the calendar. The seventh part is "Attendance and Leave". In this part, the company explains that one employee who is absence from work can involve another employee in finishing work. The worst case, it may cause more unfinished job in the company. Attendance or absence has an important role in the company's activity, and it is the responsibility of every employee towards the company. The eighth part is "Sick Leave Policy". In this part, the employees in PT. WY deserve to get $100 \%$ from their salary when they are sick and cannot perform in the company. If the employees are sick in a long period and can be proved by a note from the doctor or physician, their salary will be paid with several requirements from the company. In a certain occasion where the employees cannot perform in the company because of pregnant issues or delivery time, they deserve to get sick leave, or can be included in maternity leave. The ninth part is "Medical, Dental, and Optical Appointments". In a certain condition, medical check-up can be included as sick leaves. The employees can also use their personal leave, as a substitute of sick leave, after getting approval from the company. PT. WY also stated that every kind of medical check-up has to be done outside working hours. The tenth part is "Paid Leave". In this part, employees get approval to leave work and still get paid in several occasions, like employee's marriage, the death of family (father or mother, husband or wife, son or daughter, father or mother-in-law, or a family in the same house). Each occasion will have different number of days. In PT. WY, they do not give a specific information about funeral leave. They include it into the "Paid Leave" part in the draft. In PT. WY, the employees who want to use the funeral leave must be related immediately with the deceased. The eleventh part is "Miscellaneous Benefits". In this part, PT. WY explains that they give various benefits from time to time annually. For the detail information of the program can be discussed further with the HRD Manager. In "Miscellaneous Benefits", there is a "Break 
Room" benefit. A break room in PT. WY is a room occupied with soda, coffee, mineral water, and snack for the employees to enjoy. The company can add a fridge, sink, and microwave. This room can be used in lunch break season, and they can only consume the snack and drink in the break room or several areas that is provided by the company.

Those are the explanations of the revision I have done for the handbook for PT. WY, which also explain my contribution in order to complete the handbook. All of the revision in the draft was done with the help of theories and information from the company, as I have mentioned in the introduction chapter.

\section{CONCLUSION}

To conclude, in order to solve the problem of PT. WY which is the employees who still do not know what they can expect from the company, PT. WY needs a handbook to describe each benefit they will get as employees in PT. WY in detail. This handbook was made based on the theories Bloomfield, Schofield, and Cantesbury (2015) and Martocchio (2016), as well as the company who provided all information needed on the employee benefits draft, so it becomes a helpful guide for both the company and the employees. In order to make sure this handbook is indeed helpful for the user, I have tried not only to complete the contents of the handbook, but also to make it as detailed and clear as possible.

There are three kinds of revision that I have done in the draft of employee benefits, which are major revision, minor revision, and no revision. In the major revision, I added further explanation to make it complete and as clear as possible for the reader. I also added some subchapters or other benefits which are not written in the draft. In the minor revision, I added some small details to make the explanation better or more understandable. Finally, I did not make any revision nor add any further explanation to the information which are already clear and detailed.

By having a handbook on employee benefits, I hope both the company and the employees can make use of the handbook effectively and efficiently. I also hope that this handbook can be useful not only for a short term, but also for long term. Lastly, with this handbook, the employees are expected to understand better about all the employee benefits written in the handbook.

\section{REFERENCE}

Bloomfield, A., Schofield, P., \& Cantesbury, M. (2005). Panduan rekrutmen. Jakarta: Prestasi Pustaka Publisher.

Heathfield, S. M. (2019, January 13). The purpose of an employee handbook. Retrieved 30 January 2019 from The Balance Careers: https://www.thebalancecareers.com/whatdoes-an-employee-handbook-do-for-you-1918123

Martocchio, J. J. (2006). Employee benefits: a primer for human resource professionals. New York: McGraw-Hill Companies, Inc.

Mayangsari, A. S. (2016). Hearty Complaint Handling. Jakarta: Gramedia Pustaka Utama.

Snell, S., \& Bohlander, G. (2010). Principles of human resource management. China: SouthWestern Cengage Learning.

Werner, J. M., \& DeSimone, R. L. (2006). Human Resource Development. United State of America: Thomson South-Western. 